\title{
ANÁLISE DE CONTEÚDO INFORMACIONAL: EVIDÊNCIAS DE FATORES DE RISCO EM COMPANHIAS ELÉTRICAS DURANTE UMA CRISE HÍDRICA
}

\section{ANALYSIS OF THE INFORMATIONAL CONTENT: EVIDENCE OF RISK FACTORS IN ELECTRICAL COMPANIES DURING A WATER CRISIS.}

0 artigo foi aprovado e apresentado no XVIII USP International Conference in Accounting realizado de 25/07 a 25/07 de 2018, em São Paulo (SP).

\section{RESUMO}

O estudo tem como objetivo analisar a configuração do conteúdo informacional divulgado nos formulários de referência relacionado aos fatores de risco das empresas do setor elétrico diante de uma crise hídrica os quais foram categorizados conforme Resolução da CVM 480/2009. Para a análise dos dados, utilizou-se da técnica de estatística descritiva, teste não paramétrico de Kruskal-Wallis, além da técnica de análise de conteúdo. Os resultados evidenciaram que há uma diversidade de riscos divulgada pelas companhias. Contudo, esta divulgação, mesmo que em tese, atenda os aspectos normativos, é realizada predominantemente de forma narrativa e descritiva, sem ser consubstanciada em números e valores. Assim, muitos riscos evidenciados servem apenas como alerta, fazendo com que as empresas não divulgam o nível em que sua ocorrência é suscetível. São exemplos de riscos divulgados: (i) decisões desfavoráveis em processos judiciais; (ii) impossibilidade de implementar totalmente a estratégia dos negócios e (iii) influência significativa do acionista controlador e possíveis conflitos de interesse. Além disso, as companhias evidenciaram acerca dos cenários hidrológico e político atípicos no Brasil, a forte influência do Governo no setor e a insuficiência de eletricidade e consequente racionamento. Os resultados também revelam que as empresas praticamente não alteram suas políticas de evidenciação de um período para o outro e que existe certa padronização das informações divulgadas nos três períodos analisados, independente do cenário político, econômico e social.

Palavras-chaves: Evidenciação; Fatores de risco; Setor Elétrico; Crise Hídrica.

\begin{abstract}
The study aims at analyzing the configuration of the informational content disclosed in the reference forms related to risk factors of companies in the electricity sector in the face of a water crisis which were categorized, according to CVM Resolution 480/2009. For data analysis, it was used descriptive statistics technique, Kruskal-Wallis non-parametric test, in addition to the content analysis technique. The results showed that there is a diversity of risks disclosed by the companies. However, this disclosure, even if in theory meets the normative aspects, is carried out predominantly in a narrative and descriptive manner, without being substantiated in numbers and values. Thus, many evidenced risks serve only as a warning, making companies do not disclose the level at which their occurrence is susceptible. Examples of disclosed risks are: (i) unfavorable decisions in lawsuits; (ii) inability to fully implement the business strategy and (iii) significant influence by the controlling shareholder and possible conflicts of interest. In addition, the companies highlighted the hydrological and political scenarios, which are atypical in Brazil, the strong influence of the Government in the sector and the insufficiency of electricity and consequent rationing. The results also reveal that companies practically do not change their disclosure policies from one period to the next. There is a certain standardization of the information disclosed in the three analyzed periods, regardless of the political, economic and social scenario.
\end{abstract}

Keywords: Disclosure; Risk Factors; Electrical Sector; Water Crisis. lago França Lopes

Doutorando em Contabilidade pela Universidade Federal do Paraná (UFPR) Mestre em Contabilidade pela UFSC. Endereço Universidade Federal do Paraná Av. Prefeito Lothário Meissner 632 - Campus III - Jardim Botânico. CEP: 80210-170 - Curitiba/PR - Brasil. E-mail: iagofrancalopes@gmail.com. Telefone: +55 (41) 99154-0930

\section{Vanderlei dos Santos}

Doutor em Contabilidade pela Universidade Federal de Santa Catarina (UFSC). Endereço: Universidade Federal de Santa Catarina, Campus Reitor João David Ferreira Lima, s/n, Bairro Trindade. CEP 88040-970 - Florianópolis, SC - Brasil. E-mail: vanderleidossantos09@gmail.com. Telefone: +55 (48) 3721-6608

\section{Darci Schnorrenberger}

Doutor em Engenharia de Produção pela Universidade Federal de Santa Catarina (UFSC). Professor do Programa de Pós-Graduação em Contabilidade da Universidade Federal de Santa Catarina UFSC Endereço: Universidade Federal de Santa Catarina, Campus Reitor João David Ferreira Lima, s/n, Bairro Trindade. CEP: 88040-970 - Florianópolis, SC - Brasil. E-mail: darcisc@gmail.com. Telefone:+55 (48) 3721-6634.

\footnotetext{
Valdirene Gasparetto

Doutora em Engenharia de Produção pela Universidade Federal de Santa Catarina (UFSC). Professora do Programa de Pós-Graduação em Contabilidade da Universidade Federal de Santa Catarina UFSC Endereço: Universidade Federal de Santa Catarina, Campus Reitor João David Ferreira Lima, s/n, Bairro Trindade. CEP. 88040-970 - Florianópolis, SC - Brasil. E-mail: valdirene.gasparetto@ufsc.br. Telefone: +55 (48) 3721-6608.
} 


\section{INTRODUÇÃO}

A crise hídrica enfrentada pelo Brasil, com início em 2013 é resultado de problemas ambientais agravados com questões econômicas e sociais. A partir desse reconhecimento, as organizações passaram a reformular suas estratégias com vistas a responder a estas contingências de modo alinhado. Nesse cenário, a análise dos fatores de risco contribui para esse alinhamento, uma vez que a divulgação dos fatores de risco envolvidos no processo organizacional é determinante para o desenvolvimento das estratégias competitivas e na concepção de informações para atender os usuários. Estudos (Dantas, Rodrigues, Rodrigues \& Capelletto 2010; Fernandes, Souza \& Farias, 2010; Zonatto \& Beuren, 2010; Klann, Kreuzberg \& Beck, 2014; Pamplona, First, Haagm \& Silva, 2020) que tangenciam esse escopo indicam que compreender os fatores de risco pertinentes a uma organização contribui para o processo de tomada de decisão dos usuários da informação contábil e oferece mecanismos aos gestores para gerenciarem os riscos organizacionais.

Setores e subsetores da economia que são regulados merecem destaque quando a temática é evidenciação de fatores de risco, uma vez que sofrem influência do Estado. Neste contexto insere-se o setor elétrico, regulamentado no Brasil pela Agência Nacional de Energia Elétrica. Assim, reconhecer o comportamento desse regulador no que tange a comunicação com os demais usuários da informação contábil a respeito de fatores de risco é relevante, tanto para os investidores como para o próprio normatizador, visto que tal cenário apresenta-se como uma resposta da forma com que a empresa tem reagido à liberdade proporcionada pela Instrução CVM n $480 / 09$ no escopo de fatores de risco.

No Brasil, pesquisas envolvendo as companhias elétricas com a evidenciação de riscos são esparsas, apesar da importância do tema e relevância econômica e social do setor (Laudelino \& Fernandes, 2008; Fernandes, Souza \& Farias, 2010; Pamplona et al., 2020). Diante dos resultados já socializados, nota-se que as empresas brasileiras já demonstraram não evidenciar informações palpáveis sobre a gravidade da ocorrência de riscos, nem mesmo informações sobre gerenciamento e mecanismos de controle adotados no momento de lançamento de título (Laudelino \& Fernandes, 2008). Assim, atendem apenas o normatizador por meio de narrativas pouco informativas (Fernandes, Souza e Farias, 2010) e tendem a evidenciar maior nível de informação diante de um nível de endividamento elevado (Pamplona et al., 2020).

Como uma tentativa de verificar a ocorrência de mudança de caráter informativo pelas companhias elétricas sobre fatores de risco torna-se salutar resgatar que no período de 2013 e 2014 o setor esteve imerso em uma crise hidrológica. Esta contingência tem características capazes de alterar as narrativas sobre fatores de risco praticados pelas empresas, pois alinham-se às proposições de Miihkinen (2013) ao sinalizar que em períodos de crises econômicas, por exemplo, os relatos de riscos passam a compor o escopo informacional dos investidores em virtude de uma associação deste com a minimização da assimetria informacional, a qual paira sobre agente e principal.

Diante desse contexto, emerge a seguinte questão: Qual a configuração do conteúdo informacional divulgado nos formulários de referência sobre os fatores de risco das companhias elétricas listadas na Brasil Bolsa Balcão $[\mathrm{B}]^{3}$ diante de uma crise hídrica? Assim, o estudo objetiva analisar a configuração do conteúdo informacional divulgado nos formulários de referência relacionados aos fatores de risco das empresas do setor elétrico diante de uma crise hídrica.

A relevância do tema está inscrita sob duas perspectivas. Primeira, discorre sobre gerenciamento de riscos evidenciados por empresas do setor elétrico, uma vez que conhecer tal discussão pode contribuir para o aperfeiçoamento das práticas de gestão de riscos. Ademais, compreender esse cenário a partir de uma perspectiva contingencial fornece contribuições para visualizar os desdobramentos de uma crise hídrica no que tange à gestão empresarial, precificação do mercado e prestação do serviço ao consumidor, impactando, direta ou indiretamente, no bem-estar e qualidade de vida da sociedade. Já a segunda relevância da presente investigação incide sob a ótica da governança corporativa, na qual a evidenciação dos riscos organizacionais é tratada como um meio limitador da transferência de recursos dos controladores para os minoritários tornando-os mais evidentes (Raffournier, 1995). Assim, faz-se necessário a ampliação desse recurso de modo que os usuários externos sintam-se atendidos em termos informacionais.

A pesquisa avança, frente as pesquisas já disponíveis (Laudelino \& Fernandes, 2008; Fernandes, Souza \& Farias, 2010; Pamplona et al. (2020). À medida que considera a crise hídrica vivenciada pelo setor elétrico como uma contingência, busca-se nos relatos sobre riscos, evidências das ações das empresas diante deste contexto, reconhecendo que uma aproximação com os usuários externos por meio dos relatos de risco é uma resposta dos gestores em relação à seleção adversa de informação, a qual visa estabelecer um mercado competitivo e baseado na eficiência.

\section{INFORMAÇÃO CONTÁBIL}

Verrecchia (2001), em sua taxonomia sobre divulgação em contabilidade, infere que há três categorias de pesquisas sobre a temática. A primeira discorre sobre divulgação baseada na associação. A segunda categoria pesquisa sobre divulgação baseada no julgamento enquanto a terceira pesquisa sobre divulgação baseada na eficiência. Em essência, a divulgação de informação contábil busca estabelecer um canal de comunicação direta com os usuários da informação. Assim, os gestores podem fazer uso de elementos qualitativos e quantitativos da linguagem, a fim de comunicar o processo de continuidade e mudança organizacional aos usuários da informação.

Para a compreensão desses processos de divulgação da informação contábil e do conteúdo narrado pelos gestores aos usuários existe um esforço constante de pesquisadores (Salotti \& Yamamoto,2005; Dal Magro, Filipin \& Fernande, 2015; Fiirst et al., 2017; Faria, Andrade \& Gomes, 2018; Jin, 2020). Estes, por sua vez, dispõem de uma pluralidade de 
demonstrativos financeiros obrigatórios ou não-obrigatórios. Dentre estes demonstrativos estão: (i) Balanço Patrimonial; (ii) Demonstração de Resultado; (iii) Demonstração dos Fluxos de Caixa; (iv) Demonstração de Mutação do Patrimônio Líquida; (v) Demonstração do Valor Adicionado; (vi) Notas Explicativas; (vii) Relatório da Administração; e (viii) Formulário de Referência (FR).

Muitos dos demonstrativos financeiros possuem caráter obrigatório, no entanto não passam por um processo de auditoria. Tais fatos convencem os usuários que a elaboração destes é mais livre por parte das empresas e permitem que o gestor exerça com maior veemência a sua discricionariedade. Alinha-se a esta perspectiva o FR. O FR representa um documento periódico previsto na Instrução CVM n 480/09. Este documento tem sido utilizado pelo campo contábil como uma forma de identificar os níveis de informações a respeito das mais diferentes tipologias de informação (CVM, 2009).

Dessa forma, alinhando a proposta desta pesquisa à taxonomia de Verrecchia (2001) ilustra-se que um diagnóstico nos FR pode demonstrar com maior liberdade a disponibilidade de informações sobre fatores de risco aos usuários e contribuir para a evolução de comportamentos de transparências entre as empresas do setor elétrico. O principal motivo para a divulgação a respeito das informações de risco nos FR é o caráter obrigatório da Instrução da CVM n $480 / 2009$. No entanto, as narrativas também podem ser conduzidas pela liberdade e discricionariedade dos elaboradores, visto a característica do formulário.

\section{FATORES DE RISCO}

Como uma forma de oferecer aos usuários externos e informações pertinentes a essa particularidade das organizações, a CVM, por meio da Instrução $n^{\circ} 480 / 2009$, dispõe sobre o registro de emissores de valores mobiliários admitidos à negociação em mercados regulamentados de valores mobiliários. Nela, determina-se que dentre o conteúdo do FR as empresas privilegiem também informações em relação aos fatores de risco (CVM, 2009).

As menções elencadas no FR em relação aos riscos correspondem a descrever fatores de risco que possam influenciar a decisão de investimento, em especial, aqueles relacionados: a) ao emissor; b) ao seu controlador, direto ou indireto, ou ao grupo de controle; c) aos seus acionistas; d) as suas controladas e coligadas; e) aos seus fornecedores; f) aos seus clientes; g) aos setores da economia nos quais o emissor atue; h) à regulação dos setores em que o emissor atue; e i) aos países estrangeiros onde o emissor atua (CVM, 2009). A Figura 1 apresenta as definições constitutivas referente as recomendações a serem divulgadas no que tange fatores de riscos.

Figura 1- Fatores de Riscos

\begin{tabular}{|c|c|}
\hline $\begin{array}{l}\text { Descrição dos } \\
\text { fatores de risco }\end{array}$ & Definição Constitutiva \\
\hline Relevância & $\begin{array}{l}\text { Neste item devem ser expostos, em ordem de relevância, quaisquer fatores de risco que possam influen- } \\
\text { ciar a decisão de investimento, em especial, aqueles relacionados com o emissor e seu controlador, direto } \\
\text { ou indireto, ou grupo de controle, seus acionistas, suas controladas e coligadas, seus fornecedores, seus } \\
\text { clientes, com os setores da economia nos quais o emissor atue e sua respectiva regulação e com os países } \\
\text { estrangeiros onde o emissor atua. }\end{array}$ \\
\hline Matéria & $\begin{array}{l}\text { Cabe esclarecer que as matérias constantes das letras "a" a "i" consistem em uma lista exemplificativa. } \\
\text { Assim, ao preencher este campo do formulário de referência, o emissor deve discorrer sobre os fatores de } \\
\text { risco a ele aplicáveis que possam influenciar a decisão de investimento. }\end{array}$ \\
\hline $\begin{array}{l}\text { Responsabilidades } \\
\text { do Emissor }\end{array}$ & $\begin{array}{l}\text { O emissor poderá deixar de mencionar matérias relacionadas nas letras "a" a "i” deste item que não lhe } \\
\text { são aplicáveis, mas deverá acrescentar outras matérias não previstas na lista exemplificativa que sejam } \\
\text { relevantes em suas atividades e capazes de influenciar a decisão de investimento. }\end{array}$ \\
\hline $\begin{array}{c}\text { Aplicação Norma- } \\
\text { tiva }\end{array}$ & $\begin{array}{l}\text { Todos os fatores de risco aplicáveis ao emissor deverão ser descritos sem mitigação ou omissão de in- } \\
\text { formações relevantes. Os fatores de risco deverão ser claramente identificados e descritos em linguagem } \\
\text { clara e objetiva, de forma a permitir sua compreensão pelo investidor, devendo ser também comentados } \\
\text { seus possíveis impactos sobre o emissor. }\end{array}$ \\
\hline
\end{tabular}

Fonte: Elaborado com base no Ofício-Circular/CVM/SEP/N007/2011 (2011, p. 16)

A partir da Figura 1 ilustra-se que a decisão quanto as divulgações dos fatores de riscos devem consubstanciar-se em atender os parâmetros de relevância, matéria, responsabilidade do emissor e aplicação normativa. A própria Instrução 480 (CVM, 2009) não apresenta definições constitutivas de cada um dos fatores de risco que incentiva que as empresas realizem a divulgação, ao contrário, evidencia que "devem ser expostos, em ordem de relevância, quaisquer fatores de risco [grifo nosso] que possam influenciar a decisão de investimento” Posto isso, observa-se que a mesma concede liberdade para que os gestores possam tomar decisão quanto aos fatores a serem divulgados, desde que atendam o item o qual é elencado para esta investigação de 'Responsabilidade do Emissor'. 


\section{EMPIRISMO: SETOR ELÉTRICO}

Alinhando a perspectiva dos fatores de risco à literatura de divulgação no setor elétrico nota-se uma incipiência de pesquisa. Este cenário está consubstanciado em investigações de Fernandes, Souza e Farias (2010) e Klann, Kreuzberg e Beck (2014). Com vistas a contribuir com a redução da incipiência desse alinhamento e buscar em outros segmentos pesquisas que discutam os aspectos relacionados à evidenciação dos fatores de risco, nota-se um campo emergente e ao mesmo tempo que tem despertado o interesse de pesquisadores, exemplos recentes desse despertar estão na pesquisa de Dal Magro, Filipin e Fernande (2015), Fïrst et al (2017), e Faria, Andrade e Gomes (2018).

Fernandes, Souza e Farias (2010) investigam se as empresas evidenciam satisfatoriamente os riscos importantes para a decisão dos investidores, no momento em que lançam ofertas de títulos no mercado de capitais brasileiro. Para tal, a pesquisa investiga 18 empresas de energia elétrica. O material de análise consiste nos prospectos definitivos de oferta de valores mobiliários das empresas pesquisadas e nas Diretrizes da CVM. Adota-se a análise de conteúdo como técnica para o levantamento de resultados, os quais sinalizam que "o nível de evidenciação, ainda não está direcionado para auxiliar os investidores na tomada de decisão” (Fernandes, Souza \& Farias, 2010, p. 78).

Klann, Kreuzberg e Beck (2014) identificam os tipos de risco evidenciados nos formulários de referência das maiores empresas de cada setor listadas na atual Brasil Bolsa Balcão. Para tal, uma taxonomia é elaborada para a identificação dos riscos de crédito, legal, de mercado, operacional, estratégico, de liquidez e ambiental. Ao adotar uma postura descritiva em relação aos dados coletados no ano de 2011 a contribuição da pesquisa está em oferecer o mapeamento da evidenciação de riscos em diversos setores demonstrando a pluralidade como estes estão dispostos nos formulários de referência.

Pamplona et al (2020) averiguaram o nível e os determinantes de evidenciação de riscos em empresas brasileiras do setor de Energia Elétrica, com base nos relatórios de referência divulgados pelas organizações, relativos ao ano de 2014. Constataram que "empresas com maiores níveis de endividamento tendem a divulgar maior quantidade de informações, pois os credores monitoram fortemente estas empresas, fazendo com que os gestores divulguem os riscos com maior intensidade" (Pamplona et al., 2020, p. 31).

Dal Magro, Filipin e Fernande (2015) discutem o nível de divulgação sobre riscos com base no COSO de empresas concessionárias de rodovias. A pesquisa adota como foco o ano de 2012 e os relatórios de administração e as notas explicativas para a construção de evidências empíricas demonstrando que "há uma baixa aderência em relação à divulgação dos riscos corporativos pelas organizações brasileiras, em específico neste caso, empresas do setor de concessão de rodovias" Ademais, "as companhias apresentam uma uniformidade, ou seja, um isomorfismo mimético em relação as evidenciações” (Dal Magro, Filipin \& Fernande, 2015, p.71).

Fïrst et al. (2017) identificam de acordo com a metodologia do COSO, o nível de evidenciação dos fatores de risco e a divulgação de deficiências do controle interno das empresas brasileiras com ADRs. A pesquisa tem como foco o período de 2014. O documento elencado para análise foi o FR. Para a análise dos dados adota-se uma abordagem descritiva combinada com testes de amostra independente. Os resultados indicam que empresas com deficiências do controle interno possuem um maior nível de evidenciação de risco de imagem.

Esta pesquisa é alicerçada no argumento de que o conteúdo informacional divulgado nos FR sobre fatores de risco diante de uma crise hídrica é um processo endógeno, pois se espera que tal conteúdo informacional divulgado seja influenciado por contingências reconhecidas neste estudo como a crise hídrica. Ademais, reconhece-se que o momento de ocorrência da divulgação é ex post, elementos que indicam esta pesquisa é construída a partir da segunda abordagem da taxonomia de Verrecchia (2001).

\section{MÉTODO}

\subsection{Delineamento da Pesquisa}

O estudo possui natureza descritiva com abordagem quali-quantitativa do problema e foi realizado com apoio de documentos de fonte secundária. $\mathrm{O}$ estudo analisa o conteúdo informacional dos formulários de referência das empresas do setor elétrico classificadas nos segmentos de geração, transmissão, distribuição e comercialização. A análise compreende o período de 2013 a 2015. A escolha deste período está em linha com o espaço temporal caracterizado pela crise hídrica (Teles, 2015; Tundisi, 2008), uma vez que se tem como objetivo analisar a configuração do conteúdo informacional divulgado nos formulários de referência relacionado aos fatores de risco das empresas do setor elétrico diante de uma crise hídrica.

A abordagem quantitativa foi utilizada em um primeiro momento para quantificar e apurar o nível de evidenciação das companhias elétricas no que concerne aos fatores de riscos conforme preceitos da Instrução da CVM n $480 / 2009$. Posteriormente, a abordagem qualitativa foi utilizada para decodificar as informações que são divulgadas nos formulários de referência sobre os fatores de riscos das companhias. A decodificação destes fatores de riscos deu-se por meio da análise de conteúdo e aproximação das narrativas realizadas. 


\subsection{População e Amostra}

A população da pesquisa compreende as 63 empresas do setor elétrico listadas na Brasil Bolsa Balcão [B] $]^{3}$. Dessas, foram excluídas nove por serem empresas holding, também foram excluídas cinco empresas caracterizadas como de participação, ou seja, já constavam no consolidado da controladora. Foram excluídas ainda, quatro empresas cujos documentos não foram localizados e uma que teve seu registro cancelado dentro do período analisado. Dessa forma, a amostra é composta por 44 empresas, conforme indicado na Figura 2.

Figura 2 - Empresas que compõem a amostra da pesquisa

\begin{tabular}{|c|c|c|c|}
\hline $\mathbf{N}^{\mathbf{0}}$ & Razão Social & $\mathbf{N}^{\mathbf{0}}$ & Razão Social \\
\hline 1 & AES SUL DISTRIB GAUCHA DE ENERGIA S.A. & 23 & CIA PIRATININGA DE FORCA E LUZ \\
\hline 2 & AES TIETE ENERGIA SA & 24 & CPFL ENERGIAS RENOVÁVEIS S.A. \\
\hline 3 & AFLUENTE GERAÇÃO DE ENERGIA ELÉTRICA S.A. & 25 & ELEKTRO - ELETRICIDADE E SERVICOS S.A. \\
\hline 4 & AFLUENTE TRANSMISSÃO DE ENERGIA ELÉTRICA S/A & 26 & CENTRAIS ELET BRAS S.A. - ELETROBRAS \\
\hline 5 & ALUPAR INVESTIMENTO S/A & 27 & ELETROPAULO METROP. ELET. SAO PAULO S.A. \\
\hline 6 & AMPLA ENERGIA E SERVICOS S.A. & 28 & EMAE - EMPRESA METROP.AGUAS ENERGIA S.A. \\
\hline 7 & CIA ENERGETICA DE BRASILIA & 29 & EDP - ENERGIAS DO BRASIL S.A. \\
\hline 8 & CIA ESTADUAL DE DISTRIB ENER ELET-CEEE-D & 30 & ENERGISA MATO GROSSO DO SUL - DIST DE ENERGIA S.A. \\
\hline 9 & CIA ESTADUAL GER.TRANS.ENER.ELET-CEEE-GT & 31 & ENEVA S.A \\
\hline 10 & CENTRAIS ELET DE SANTA CATARINA S.A. & 32 & ESPIRITO SANTO CENTR.ELETR. S.A.-ESCELSA \\
\hline 11 & CENTRAIS ELET DO PARA S.A. - CELPA & 33 & DUKE ENERGY INT. GER. PARANAPANEMA S.A. \\
\hline 12 & CIA ENERGETICA DE PERNAMBUCO - CELPE & 34 & INVESTCO S.A. \\
\hline 13 & CIA ENERGETICA DO MARANHAO - CEMAR & 35 & ITAPEBI GERAÇÃO DE ENERGIA S/A \\
\hline 14 & CIA ENERGETICA DE MINAS GERAIS - CEMIG & 36 & LIGHT SERVICOS DE ELETRICIDADE S.A \\
\hline 15 & CEMIG DISTRIBUICAO S.A. & 37 & CIA PAULISTA DE FORCA E LUZ \\
\hline 16 & CEMIG GERACAO E TRANSMISSAO S.A. & 38 & RENOVA ENERGIA S.A. \\
\hline 17 & CESP - CIA ENERGETICA DE SAO PAULO & 39 & RIO GRANDE ENERGIA S.A. \\
\hline 18 & CIA ELETRICIDADE EST. DA BAHIA - COELBA & 40 & STATKRAFT ENERGIAS RENOVAVEIS S.A. \\
\hline 19 & CIA ENERGETICA DO CEARA - COELCE & 41 & TRANSMISSORA ALIANÇA DE ENERGIA ELÉTRICA S.A. \\
\hline 20 & CIA PARANAENSE DE ENERGIA - COPEL & 42 & TERMOPERNAMBUCO SA \\
\hline 21 & CIA ENERGETICA DO RIO GDE NORTE - COSERN & 43 & TRACTEBEL ENERGIA S.A. \\
\hline 22 & CPFL GERACAO DE ENERGIA S.A. & 44 & CTEEP - CIA TRANSMISSÃO ENERGIA ELÉTRICA PAULISTA \\
\hline 22 & CPFL GERACAO DE ENERGIA S.A. & 44 & CTEEP - CIA TRANSMISSÃO ENERGIA ELÉTRICA PAULISTA \\
\hline
\end{tabular}

Fonte: Dados da pesquisa.

\subsection{Coleta e Análise dos Dados}

Para a coleta dos dados, utilizou-se de fonte documental inscrita no Formulário de Referência das empresas no período de 2013 a 2015, os quais foram extraídos do site da Brasil Bolsa Balcão [B] $]^{3}$. Na análise dos dados, utilizou-se de quatro técnicas. A primeira, inscrita na apresentação dos dados na sua forma descritiva, a partir do uso de técnica simples de estatística, a exemplo de Mínimo, Máximo, Média, Moda e Desvio-padrão.

A segunda consiste na análise categoria do conteúdo informacional divulgado nos formulários de referência relacionado a fatores de risco. Para esta técnica foi apurada a evidenciação dos fatores em nove categorias, conforme recomendação da Instrução 480 (CVM, 2009) (emissor, controlador, acionistas, controladas e coligadas, fornecedores, clientes, setores, regulação e países estrangeiros). Para tal ação, realizou-se a leitura do item 4.1 - Fatores de Riscos do Formulário de Referência de cada uma das Companhias do Setor Elétrico selecionada e categorizou-se os fatores de riscos utilizando uma escala de 0 a 3 , sendo que: (i) 0 (zero), quando o fator de risco não foi divulgado nos formulários de referência; (ii) 1 (um) quando foi divulgado nos formulários de referência em forma narrativa; (iii) 2 (dois) quando foi divulgado nos FR com apoio de números, cumulativamente a forma narrativa; (iv) 3 (três) quando foi divulgado nos formulários de referência com apoio de valor monetário, cumulativamente a forma narrativa e apoiada em números. Também se utilizou o termo "não se aplica" (NA) nos casos em que as empresas deixavam evidente esta situação, conforme orientação da CVM (2009). É válido ressaltar que o tipo de escala elencada para apurar a evidenciação dos fatores de 
risco já foi utilizado por Machado, Cruz, Takamatsu e Lima (2013), que identificaram se existem níveis diferenciados de disclosure de informações sobre impairment entre as companhias abertas brasileiras listadas, em 2009, no Novo Mercado.

A terceira técnica de análise ocorre quando o conteúdo informacional divulgado nos formulários de referência relacionado a fatores de risco das empresas do setor elétrico diante de uma crise hídrica encontra-se em planilha eletrônica e categorizado. Assim, utilizou-se do teste não paramétrico de Kruskal-Wallis para verificar se há diferença no nível de evidenciação durante o período analisado (2013 a 2015) por fator de risco. Tal teste foi aplicado devido a não normalidade dos dados, quando da aplicação do teste de Kolmogorov-Smirnov.

Por fim, a quarta técnica está consubstanciada em uma análise dos dados com exemplificações de narrativas divulgadas pelas companhias no que concerne aos fatores de risco. Estas foram selecionadas de modo aleatório, a partir do escopo de cada fator de risco, com vistas a apresentar e reforçar os achados da investigação, fato que se alinha à intuição, à imaginação e à criatividade do presente pesquisador (Freitas, Cunha, \& Moscarola, 1997) Tal prática é recorrente nos estudos que adotam análise de conteúdo no âmbito da temática de evidenciação contábil e análise de conteúdo informacional (Zonnatto \& Beuren, 2010; Beuren \& Silva, 2015; Lopes \& Beuren, 2016; Lopes, Beuren \& Dametto, 2016; Meurer, Lopes \& Musial, 2018).

\section{RESULTADOS}

\subsection{Configuração do Conteúdo Informacional}

Inicialmente foi mapeado o nível de evidenciação dos fatores de risco que possam influenciar a decisão de investimento, das companhias. Para tanto, fez-se uso de uma escala de "0" a " 3 ", como destacado nos procedimentos metodológicos. A Tabela 1 apresenta os resultados da estatística descritiva no que concerne à evidenciação por fatores de riscos.

Tabela 1- Evidenciação dos Fatores de Risco

\begin{tabular}{|c|c|c|c|c|c|c|}
\hline Fatores de Risco & Ano & Máximo & Mínimo & Média & Moda & Desvio-padrão \\
\hline \multirow{3}{*}{ Emissor } & 2015 & 3 & 1 & 1,674 & 1,000 & 0,693 \\
\hline & 2014 & 3 & 1 & 1,689 & 1,000 & 0,694 \\
\hline & 2013 & 3 & 1 & 1,556 & 1,000 & 0,652 \\
\hline \multirow{4}{*}{ Controlador } & 2015 & 3 & 1 & 1,267 & 1,000 & 0,533 \\
\hline & 2014 & 3 & 1 & 1,267 & 1,000 & 0,490 \\
\hline & 2013 & 3 & 1 & 1,205 & 1,000 & 0,456 \\
\hline & 2015 & 2 & 1 & 1,070 & 1,000 & 0,255 \\
\hline \multirow[t]{3}{*}{ Acionistas } & 2014 & 2 & 1 & 1,073 & 1,000 & 0,260 \\
\hline & 2013 & 2 & 1 & 1,077 & 1,000 & 0,266 \\
\hline & 2015 & 2 & 1 & 1,077 & 1,000 & 0,266 \\
\hline \multirow[t]{3}{*}{ Controladas ou Coligadas } & 2014 & 2 & 1 & 1,148 & 1,000 & 0,355 \\
\hline & 2013 & 3 & 1 & 1,231 & 1,000 & 0,504 \\
\hline & 2015 & 1 & 1 & 1,000 & 1,000 & - \\
\hline \multirow[t]{3}{*}{ Fornecedores } & 2014 & 2 & 1 & 1,048 & 1,000 & 0,213 \\
\hline & 2013 & 2 & 1 & 1,024 & 1,000 & 0,154 \\
\hline & 2015 & 3 & 0 & 1,413 & 1,000 & 0,709 \\
\hline \multirow[t]{3}{*}{ Clientes } & 2014 & 3 & 0 & 1,545 & 1,000 & 0,752 \\
\hline & 2013 & 3 & 0 & 1,488 & 1,000 & 0,727 \\
\hline & 2015 & 3 & 1 & 1,348 & 1,000 & 0,560 \\
\hline \multirow[t]{3}{*}{ Setor de Atuação } & 2014 & 2 & 1 & 1,304 & 1,000 & 0,460 \\
\hline & 2013 & 2 & 1 & 1,289 & 1,000 & 0,453 \\
\hline & 2015 & 3 & 1 & 1,457 & 1,000 & 0,682 \\
\hline \multirow[t]{3}{*}{ Regulação dos Setores } & 2014 & 3 & 1 & 1,370 & 1,000 & 0,638 \\
\hline & 2013 & 3 & 1 & 1,348 & 1,000 & 0,633 \\
\hline & 2015 & 1 & 0 & 0,500 & $\mathrm{NA}^{*}$ & 0,500 \\
\hline \multirow[t]{2}{*}{ Países Estrangeiros } & 2014 & 2 & 0 & 1,000 & NA & 0,816 \\
\hline & 2013 & 2 & 0 & 1,000 & NA & 0,816 \\
\hline
\end{tabular}

Fonte: Dados da pesquisa.

$\mathrm{Na}$ Tabela 1 observa-se os riscos evidenciados pelas empresas pesquisadas. Os valores inscritos em máximo/mínimo 0 apontam que o fator de risco não foi divulgado nos formulários de referência, o que acontece com os fatores de riscos relacionados aos clientes e aos países estrangeiros. De modo geral, os resultados evidenciam que as empresas nos 
três períodos analisados optam com elevada tendência em divulgar sobre fatores de riscos relacionados (a) ao emissor/ companhia; (b) a seu controlador, direto ou indireto, ou grupo de controle; (c) a seus acionistas; (d) a suas controladas e coligadas; (e) a seus fornecedores; (f) a seus clientes; (g) aos setores da economia nos quais o emissor atue; (h) à regulação dos setores em que o emissor atue; e (i) aos países estrangeiros onde o emissor atue em uma forma narrativa. Visto que a moda em todas as categorias analisadas é 1. Os itens com máximo/mínimo 2 denota que foi divulgado nos FR informações sobre fatores riscos com apoio de números, cumulativamente a forma narrativa. Em termos máximo 2 isso acontece com fatores de riscos relacionados com: acionista, controladas ou coligadas, setor de atuação e países estrangeiros.

Já os itens com máximo/mínimo 3 no período analisado indica que as empresas analisadas têm feito uso de valor monetário, cumulativamente a forma narrativa e apoiada em números para abordar as questões relacionadas aos fatores de riscos. Esse cenário é visualizado nos fatores de riscos relacionados ao emissor, controlador, cliente e regulação dos Setores. Por fim, o NA indica que para tais categorias não perfaziam o negócio o qual estava sendo analisado. A partir do exposto, em termos descritivos, as narrativas atendem a Instrução CVM n ${ }^{\circ} 480 / 2009$. Por outro lado, essa uniformidade informacional, sem evidenciação numérica, pode não suprir às demandas informacionais de quem toma decisões, pois um sistema de divulgação de informações tem por objetivo promover a concorrência, garantindo assim a justiça do mercado (Jin, Chen, Wang, Yu \& Long, 2020).

Praticamente não há diferenças nas políticas de evidenciação durante o período analisado. Isso implica em duas medidas: que as companhias não estão aperfeiçoando suas práticas de evidenciação dos fatores de risco ou que o período de crise hídrica contribuiu para tal cenário. Além disso, durante a análise de conteúdo, percebeu-se que as divulgações dos fatores de risco pelas empresas não apresentam uma característica informacional específica. A maioria é realizada de forma genérica. Estes resultados convergem com os estudos de Laudelino e Fernandes (2008) e Fernandes, Souza e Farias (2010), em que foi sinalizado que existe um nível incipiente de transparência se comparado com as práticas internacionais. Essa uniformidade alinha-se também às perspectivas Dal Magro, Filipin e Fernandes (2015) quanto a presença do isomorfismo mimético presente nas evidenciações.

Apresenta-se a evidenciação da Light Energia S.A. (2015) no que concerne aos riscos de condições hidrológicas desfavoráveis, conforme Figura 3.

Figura 3- Narrativa de Risco Light Energia S.A.

Os resultados da Companhia podem ser afetados negativamente por condições hidrológicas desfavoráveis, risco de escassez de energia elétrica, e possibilidade de racionamento no país.

(Light Energia S.A., 2015, p. 23).

A empresa não descreve especificidades deste risco, quanto a condições hidrológicas desfavoráveis. Por exemplo, quanto do resultado da companhia pode ser afetado por condições hidrológicas desfavoráveis? Qual a probabilidade disto acontecer? Estas informações não são divulgadas e não são consideradas tempestividade sobre as mesmas. Esta forma de evidenciação não é exclusiva para os riscos relacionados aos setores e se estende aos demais tipos de riscos, conforme Figura 4.

Figura 4- Narrativa de Risco relacionado à companhia/emissor - Duke Energy Int Geração Paranapanema S.A.

Um risco inerente à operação da Companhia [...] é a possibilidade de rompimento ou galgamento das barragens, o que pode causar, no caso das instalações que tem construções e habitantes em suas proximidades, inundações nas propriedades vizinhas e até mesmo acidentes [..]. Nessas hipóteses, a Companhia pode ser acionada judicialmente [..] (Duke Energy Int Geração Paranapanema S.A., 2015, p. 17).

Depreende-se que a empresa apenas reconhece que pode ser afetada por um eventual rompimento ou galgamento das barragens, porém, não descreve a probabilidade de ocorrência deste risco e nem seus efeitos em termos econômico-financeiros. Esses questionamentos partem da ideia que os usuários externos desejam informações que garantam a transparência, e permitam avaliar e alocar recursos de modo equitativo no mercado. Com parcimônia é questionável se todos os riscos evidenciados pelas companhias de fato existem ou se existe uma tendência de divulgação de determinados tipos de informações realizadas de forma contínua.

Verifica-se que as informações não subsidiam a tomada de decisão, uma vez, que são genéricas, não são consubstanciadas em números e valores e nem são divulgadas quando ocorre nas empresas pesquisadas. Reitera-se, novamente, que as críticas realizadas não são exclusivamente para as companhias cujos relatos foram expostos, mas para o setor como um todo, visto a padronização da forma de divulgação dos fatores de risco. Fernandes, Souza e Faria (2010) também constataram que as empresas do setor elétrico atendem as diretrizes emitidas pela CVM no que concerne à evidenciação de riscos. Porém, não divulgam informação alguma sobre a gravidade dos riscos. Complementado tal inferência, 
Fernandes, Souza e Farias (2010) também questionam a real efetividade das informações divulgadas pelas empresas.

Com vistas a responder sobre a existência de uma tendência de divulgação de informações foi utilizado o teste não paramétrico de Kruskal-Wallis para comparar se há diferença nas políticas de evidenciação entre os períodos, conforme Tabela 2.

Tabela 2 - Teste não paramétrico de Kruskal-Wallis

\begin{tabular}{|c|c|c|c|c|c|c|c|}
\hline Teste/Fatores de Risco & Emissor & Controlador & Acionista & Fornecedores & Clientes & Setor & Regulação \\
\hline Qui-quadrado & 1,193 & 0,788 & 0,115 & 2,552 & 0,268 & 0,089 & 0,754 \\
Significância & 0,551 & 0,674 & 0,944 & 0,279 & 0,874 & 0,956 & 0,686 \\
\hline
\end{tabular}

Fonte: Dados da pesquisa.

Observa-se que nenhum dos fatores de risco analisados apresentou diferenças estatisticamente significativas na forma de evidenciação. Portanto, as empresas não modificam sua maneira de divulgar as informações de riscos. A variável "países estrangeiros" não foi testada porque a maioria das empresas não atua no mercado internacional. A variável "controladas ou coligadas" também não foi testada visto que uma parte considerável da amostra não divulgou tal informação por considerar não aplicável e/ou por já ter apontado os fatores de risco em tópicos anteriores.

Este resultado converge com o que foi observado durante a análise de conteúdo, em que foi constatado que as empresas praticamente mantêm seu texto de evidenciação durante o período (2013-2015). Este resultado pode ser caracterizado como intrigante e remete a alguns questionamentos, tais como: (i) Os riscos associados a este setor não são modificáveis no decorrer dos anos?; (ii) As empresas sempre estão associadas aos mesmos tipos de riscos, sendo que não há mitigação destes nos anos subsequentes ou surgimento de outros?; e (iii) Se não há alteração nas práticas de evidenciação, é necessária sua divulgação em todos os anos subsequentes?.

\subsection{Divulgação sobre Fatores de Risco}

Este tópico tem a finalidade de descrever, de forma sucinta, as informações que são divulgadas nos formulários de referência por fatores de riscos. O intuito é analisar o que as companhias elétricas estão divulgando, uma vez que conforme apontado pela literatura (Zonatto \& Beuren, 2010; Klann, Kreuzberg \& Beck, 2014; Pamplona et al., 2020), não existe uma padronização quanto aos tipos de riscos evidenciados. A Instrução da CVM 480/2009 não especifica os tipos riscos que devem ser divulgados, apenas menciona os agentes que precisam ser considerados.

Foram analisados 1.092 fatores de risco no ano de 2015. Optou-se pela análise de um único período, visto que os resultados apontaram não existir diferenças nas práticas de evidenciação. Ademais, as pesquisas envolvendo evidenciação que adotam uma abordagem qualitativa não buscam ampliar de modo substancial o período de análise, visto que o foco deste tipo de pesquisa é a constatação em profundidade (Faria, Andrade \& Gomes, 2018; Fiirst, Pamplona Haag \& Silva, 2017).

\subsubsection{Fatores relacionados à companhia/emissor}

A maior parte dos riscos está relacionada com a atividade operacional das companhias. Durante a análise de conteúdo, percebeu-se que alguns deles apresentaram relatório padrão entre as companhias, favorecendo o isomorfismo mimético (Dal Magro, Filipin \& Fernandes, 2015).

Destaca-se o risco "decisões desfavoráveis de processos judiciais", citado por $81,8 \%$ das companhias. Todavia, em raros casos é descrito o impacto destas possíveis decisões desfavoráveis. A maioria das empresas reconhece que a companhia pode ter um resultado negativo com decisões desfavoráveis. Outro risco frequentemente divulgado é sobre a impossibilidade de implementar totalmente a estratégia dos negócios, divulgado por $65,9 \%$ das companhias. Este risco é descrito sem suporte em dados financeiros e econômicos. As empresas apenas reconhecem que a estratégia do negócio pode não ser implementada devido a atual conjectura econômica. Porém, não fornecem elementos elucidativos para tal afirmação e muito menos em que medida tal situação pode ocorrer.

Outros riscos de destaque nesta categoria foram: (i) dificuldades com a operação e manutenção da usina hidrelétrica; (ii) responsabilidade objetiva por danos diretos e indiretos decorrentes da prestação de serviços de distribuição de energia elétrica; (iii) perda de receita ou aumento das despesas; (iv) incerteza na obtenção de novas concessões ou renovação das atuais; (v) dificuldade na obtenção de recursos para financiar as aquisições e investimentos; (vi) restrições contratuais à capacidade de endividamento da companhia; (vii) penalizações pela ANEEL pelo não cumprimento do contrato de concessão; e (viii) resultados operacionais dependentes de condições hidrológicas favoráveis. Destes, apresenta-se para fins de exemplificação a evidenciação realizada companhia CPFL Geração de Energia S.A. (2015) na Figura 5. 
Figura 5- Narrativa de Risco CPFL Geração de Energia S.A.

Nós podemos ser penalizados pela ANEEL se não cumprirmos com os termos contidos nos nossos contratos de concessão, que podem nos acarretar multas, outras penalidades e, dependendo da gravidade do descumprimento, o encerramento de nossas concessões.

(CPFL Geração de Energia S.A., 2015, p. 14).

A partir do relato exposto, a empresa descreve que pode ser penalizada pela ANEEL caso não cumpra com as exigências contratuais da concessão. Neste aspecto, é questionável se, de fato, a evidenciação exposta consiste em um risco real ou possível para a companhia e que pode interferir nas decisões de investimentos, visto que há cumprimento das exigências solicitadas pela ANEEL. Relatos desta forma foram realizados para outros tipos de riscos, como, perda de receita ou aumento das despesas e incerteza na obtenção e/ou renovação de novas concessões.

Também foram mencionados, porém, por poucas companhias, o impedimento de terceirizar algumas atividades, a instabilidade das taxas de inflação e de juros, as interrupções das operações ou degradação da qualidade de serviços, impossibilidade de cumprir o prazo do programa de investimento, violação de segurança de informações, deficiências nos controles internos, ocorrência de danos ambientais envolvendo as atividades da Companhia. A empresa Tractebel Energia S.A. (2015) divulgou o risco sobre a ocorrência de danos ambientais, conforme Figura 6.

Figura 6 - Narrativa de Risco Tractebel Energia S.A.

A ocorrência de danos ambientais envolvendo as atividades da Companhia pode sujeitá-la ao pagamento de custos de recuperação ambiental e indenizações. As atividades do setor de energia podem causar impactos negativos e danos ao meio ambiente (Tractebel Energia S.A. 2015, p. 18).

Indaga-se pelo exposto se a empresa está suscetível a este risco ou se apenas é uma probabilidade remota de ocorrência. Outro ponto, se não apresentado o nome da empresa em questão. Tende-se a percepção que esta narrativa caberia a qualquer empresa. A descrição desse risco pela Tractebel Energia S.A. (2015) acontece em um ambiente que não considera tempo e espaço. Nota-se que inúmeros riscos são descritos pelas companhias. O reconhecimento destes riscos está convergente com os preceitos legais de divulgação exigidos. Porém, questiona-se sua utilidade para os stakeholders, uma vez que vários riscos são mencionados, muitas vezes, de maneira genérica, sem mencionar o real impacto para a companhia e em que medida de fato ocorre nas empresas pesquisadas. Nota-se uma cultura de descrever o risco sem considerar as dimensões temporais nas narrativas.

\subsubsection{Fatores relacionados aos controladores}

Neste item, poucos riscos são relatados, na sua maioria de forma narrativa. A maior parte das empresas (35 delas) menciona sobre a influência significativa do acionista controlador e possíveis conflitos de interesse entre o controlador e demais interessados pela companhia. Destaca-se que muitas companhias possuem como controlador, o Estado e alertam que alguns interesses públicos podem prevalecer. Neste aspecto, a empresa EMAE - Empresa Metrop. Aguas Energia S.A. (2015) reconhece que mudanças no Governo do Estado de São Paulo podem resultar em modificações na composição dos conselhos e da diretoria.

\subsubsection{Fatores relacionados aos acionistas}

Os riscos mais divulgados nesta categoria foram: (i) não garantia de pagamento de dividendos e juros sobre capital próprio, item mencionado por 20 empresas; (ii) diluição da participação dos investidores no capital da companhia, relato de 14 empresas; (iii) volatilidade e falta de liquidez do mercado de valores mobiliários brasileiro, narrativas presentes nos formulários de referência de 10 empresas. Também há riscos que foram apontados exclusivamente por uma empresa, como, por exemplo, acontecimentos políticos, econômicos e sociais, bem como a percepção de riscos em outros países, interferindo nas ações da companhia.

Ressalta-se que nesta categoria, a evidenciação dos riscos ocorreu na maioria dos casos, de forma breve, sem amparo em números e valores. Para fins de exemplo, apresenta-se uma divulgação realizada pela Companhia Energética de São Paulo (2015), conforme Figura 7.

Figura 7 - Narrativa de Risco Companhia Energética de São Paulo

Os acionistas da Companhia podem não receber dividendos ou juros sobre capital próprio. Dependendo dos resultados futuros, os titulares de ações da Companhia poderão não receber dividendos ou juros sobre o capital próprio se a mesma não apurar lucros.

(Companhia Energética de São Paulo, 2015, p. 18). 
Observa-se que a companhia apenas menciona que os acionistas "podem" não receber os dividendos ou juros sobre capital próprio. No entanto, não descreve a probabilidade deste acontecimento, não apresenta os resultados que levaram a esta inferência, sendo que se observou que esta informação praticamente é divulgada em todos os anos analisados de modo uniforme e sem alterações. Basicamente, um relatório é réplica do que foi divulgado no ano anterior. $\mathrm{O}$ mesmo acontece com o fator de risco de necessidade de capital futuro e/ou diluição do capital. As empresas não apresentam os elementos que levaram a esta conclusão e nem o grau e/ou nível de exposição a este risco.

\subsubsection{Fatores relacionados às controladas ou coligadas}

Este item apresenta certa diversificação nos riscos divulgados, porém, em menor quantidade comparativamente aos itens anteriores. Ao todo, foram feitas 50 menções pelas companhias. Percebeu-se que alguns riscos divulgados constam também em outros tópicos. Como riscos divulgados, destacam-sea título de ilustração: (i) as controladas da Companhia são dependentes de prestadores de serviços terceirizados para a operação e manutenção de suas instalações; (ii) parte dos resultados da Companhia depende da operação de determinadas controladas e controladas em conjunto que ainda não estão em operação. Caso o início das operações de qualquer controlada e controlada em conjunto não ocorra nas datas previstas, a Companhia poderá sofrer impacto adverso nos seus resultados; (iii) participações em sociedades de propósito específico ("SPEs") poderão resultar em riscos de natureza fiscal; (iv) incapacidade de repasse integral dos custos de compra de energia elétrica; (v) impossibilidade de controlar com sucesso as perdas de energia; (vi) possibilidade de não extrair as sinergias que foram planejadas entre coligadas e controladas; (vii) suspensão ou cancelamento de benefícios fiscais federais e estaduais; (viii) dificuldades em manter os resultados esperados na aquisição de novas empresas; (ix) condições hidrológicas atuais; e (x) prorrogação e caducidade de concessões.

Denota-se pelos riscos expostos que alguns são exclusivamente de transações com coligadas e controladas e estão atrelados a este tipo de investimentos. Outros riscos são de natureza operacional, comumente divulgado nos fatores de risco relacionados ao emissor. Também há aqueles mais pluralistas, que contemplam o ambiente econômico e natural do momento.

\subsubsection{Fatores relacionados aos fornecedores}

Nesta categoria, os riscos mais destacados foram custos de contratação, risco de escassez de fornecedores e incapacidade e/ou indisponibilidade dos fornecedores. Também foram apontados (i) problemas com as empresas terceirizadas; (ii) eventuais atrasos ou falhas na prestação de serviços pelas construtoras contratadas e no fornecimento de máquinas e equipamentos; (iii) equipamentos não serem entregues a contento ou os serviços não serem executados de acordo com as especificações e padrões mínimos relativos a cada empreendimento, o que pode ocasionar um impacto adverso nas receitas e resultados operacionais; (iv) eventuais falhas na transmissão de energia pelas transmissoras fornecedoras; (v) responsabilidade principal ou solidária das dívidas trabalhistas de terceirizados; (vii) falta de qualidade dos serviços e materiais; (viii) ausência de fontes alternativas de suprimento de matéria-prima para serem usadas pelas suas usinas térmicas e nucleares; (ix) não atendimento de disposições contratuais; e (x) inexistência de um fornecedor para a água.

O relato apresentado a seguir é da Itapebi Geração de Energia S.A. (2015) no qual reconhece como risco a inexistência de um fornecedor de água e os custos de contratação, conforme Figura 8.

Figura 8 - Narrativa de Risco Itapebi Geração de Energia

O principal insumo utilizado pela Itapebi é a água, que é proveniente do aproveitamento hidrelétrico, alvo da concessão. No Brasil, a utilização dos recursos hídricos é regulada pela a Agência Nacional de Águas - ANA. Embora a ANA regule e fiscalize a utilização dos recursos hídricos, não existe um fornecedor para a água. I. Custos de contratação podem variar de acordo com a demanda de mercado devido à limitação do número de fornecedores (Itapebi Geração de Energia S.A., 2015, p. 20).

Nos relatórios ficou evidente o risco do custo de contratação e o risco de escassez de fornecedores. Contudo, as empresas não relatam as ações para mitigar tais riscos. Em muitos relatórios, a divulgação destes riscos praticamente permanece inalterada durante o período analisado.

\subsubsection{Fatores relacionados aos clientes}

Neste tópico o risco mais apontado pelas companhias foi sobre eventuais inadimplências e/ou a falta de capacidade de pagamento de clientes, destacado por 31 empresas, representando 70,5\% da amostra. Com menor grau de citação, elencam-se, ainda, os riscos relacionados a fraudes no consumo de serviços, a concorrência dos consumidores considerados "livres", a falta de manutenção e conservação das redes de distribuição, ausência de receitas diversificadas, entre outros. Neste item, também predomina a divulgação de forma narrativa, embora, em alguns casos, as empresas apoiam-se em alguns números, conforme narrativa da Companhia Paranaense de Energia (2015), conforme Figura 9. 
Figura 9 - Narrativa de Risco Companhia Paranaense de Energia

Em 31 de dezembro de 2014, nossos recebíveis vencidos junto aos consumidores finais somavam aproximadamente $\mathrm{R} \$ 393,3$ milhões no total, ou 9,0\% de nossa receita proveniente de vendas de energia aos consumidores finais no exercício findo em 31 de dezembro de 2014, e nossa provisão para devedores duvidosos relacionada com esses recebíveis totalizou $\mathrm{R} \$ 158,2$ milhões.

(Companhia Paranaense de Energia, 2015, p. 17).

Observa-se que a empresa destacou a representatividade dos recebíveis sobre a receita, bem como, os valores totalizados em perdas estimadas para crédito de liquidação duvidosa. Contudo, ainda a informação não está completa, visto que informações de períodos anteriores são necessárias para conotar a inadimplência dos clientes.

\subsubsection{Fatores relacionados ao setor de atuação}

Nesta categoria existe uma ampla variedade de riscos divulgados, sendo destaque a escassez de energia elétrica, inclusive em razão de baixos índices pluviométricos e outros fatores climáticos, e o consequente racionamento de energia, conforme divulgado pela Energisa Mato Grosso do Sul - Distribuidora de Energia S.A. (2015), conforme Figura 10.

Figura 10 - Narrativa de Risco Energisa Mato Grosso do Sul - Distribuidora de Energia S.A

O impacto de uma escassez de energia e consequente racionamento de energia, como o que ocorreu em 2001 e 2002, poderá causar um efeito adverso significativo sobre os negócios e resultados operacionais da Companhia. A energia hidrelétrica é a principal fonte de energia no Brasil. A capacidade de operação das usinas hidrelétricas depende do nível de armazenamento de água em seus reservatórios e, consequentemente, dos índices pluviométricos (Energisa Mato Grosso do Sul - Distribuidora de Energia S.A., 2015, p. 20).

Cabe destacar que praticamente ficou institucionalizada a divulgação sobre a potencial falta de eletricidade e o consequente racionamento de energia elétrica. Porém, nem sempre esta divulgação vem acompanhada com informações tempestivas e precisas. Além disso, a instabilidade política e econômica do Brasil foi destaque realizado por $45,5 \%$ da amostra. Muitas empresas divulgaram sobre a forte interferência do Governo Federal no setor. Inclusive, relatos sobre a operação da Lava Jato foi alvo de divulgação de poucas companhias. A instabilidade das taxas de inflação, juros, cambio e moeda e alterações nas leis tributárias brasileiras e sobre encargos setoriais também foram evidenciados por algumas companhias.

\subsubsection{Fatores relacionados à regulação}

Neste item é enfatizado sobre a ampla regulamentação do setor, com destaque para alguns riscos, como, por exemplo: alteração e amplas leis na regulamentação expedida pela ANEEL, alterações nas leis e regulamentos ambientais, alterações na legislação tributária do Brasil, o poder discricionário da ANEEL na determinação das tarifas. Porém, as empresas apenas divulgam que a regulamentação pode vir sofrer alterações, mas não apontam dados concretos para estas suposições, ou seja, permanece na especulação. Também relatam sobre a possibilidade de contestação legal quanto à estrutura regulatória do setor, conforme divulgação da Rio Grande Energia S.A. (2015), conforme Figura 11.

Figura 11 - Narrativa de Risco Rio Grande Energia S.A

A estrutura regulatória sob a qual operamos está sujeita a contestação legal. O governo brasileiro implementou mudanças fundamentais na regulação do setor elétrico na legislação aprovada em 2004, conhecida como a Lei do Novo Modelo do Setor Elétrico. Contestações quanto à constitucionalidade da Lei do Novo Modelo do Setor Elétrico ainda estão pendentes perante o Supremo Tribunal Federal. (Rio Grande Energia S.A., 2015, p. 18).

Este item enfatiza que o setor é altamente regulado, que existe discricionariedade do poder concedente e que nem todos os programas são rentáveis para as companhias, como por exemplo, o programa de universalização do Governo Federal. Este programa foi criado pelo Governo em 2002, e requer o investimento das distribuidoras de energia elétrica no atendimento a determinados grupos de consumidores, de acordo com certas metas pré-definidas. De acordo com esse programa, "as distribuidoras de energia devem arcar com os custos de ligação para consumidores cuja potência declarada dos equipamentos elétricos não ultrapasse 50 kW" (CEMAR, 2015, p. 17). 


\subsection{Discussão}

Miihkinen (2013) sinaliza que em períodos de crises econômicas os relatórios sobre risco ganham maior notoriedade entre os investidores e estes tendem a se beneficiar destas informações para tomada de decisão. No entanto, de acordo com as evidências construídas nesta pesquisa as empresas do setor elétrico tendem a demandar esforços apenas para atender a CVM. A partir desta incongruência de cenários, questiona-se qual a real utilidade do FR no que tange a apresentar elementos sobre fatores de risco que influenciem a tomada de decisão?

A regulamentação, discutida nesta pesquisa, deixa espaço para interpretações, pois a recomendação feita pela Instrução CVM 480/2009 é que a empresa descreva os fatores de risco que possam influenciar a decisão de investimento. Assim, a configuração e as decisões finais de divulgação são de responsabilidade da empresa e diante do cenário identificado, questões como, a capacidade da informação fazer diferença nas decisões tomadas pelos usuários e a capacidade da informação apresentar valor preditivo ou valor confirmatório permanecem em aberto e o exame das mesmas mostra-se como uma questão de pesquisa viável.

A pesquisa de Miihkinen (2013, p.19) evidenciou que "a divulgação de riscos fornece informações críticas aos investidores porque a assimetria de informações em relação aos riscos da empresa efetivamente dificulta a avaliação da empresa", ou seja, os investidores, ao terem contato com informações de risco sobre a empresa, podem tomar melhores decisões no que tange a sua avaliação. Transladando esse argumento, aos dados elencados na pesquisa nota-se que apenas a atendimento ao legislador de modo genérico pouco contribui para as decisões dos investidores. Diante disso questiona-se qual a real relevância da divulgação de riscos para investidores no mercado de capitais brasileiro?

Diante desses dados espera-se que as informações de riscos ao longo de tempo respondam às contingências ambientais vivenciadas pelas empresas analisadas, de modo a conduzir o usuário a notar as informações contábeis divulgadas como úteis e aliadas do processo de decisão. É certo que a discricionariedade do gestor proporcionada pela CVM 480/2009 representa um elemento a ser questionado e/ou investigado, uma vez que "na hipótese de existência de custos e/ou incerteza, os gerentes decidem divulgar ou não determinada informação [...], apesar do fato de os agentes de fora da empresa interpretarem informação não divulgada de maneira racional” (Salotti \& Yamamoto, 2005, p. 64).

Assim, esta análise é fruto do ambiente institucional em que o relatório de risco é regulado e na sua maioria o controlador das empresas é o Estado. Alinhando essa perspectiva à Teoria da Divulgação de Verrecchia (2001) reconhece-se que a divulgação sobre fatores de risco é um processo endógeno e assume-se que a administração opta em não divulgar tais informações. Assim, "qualquer entidade que esteja cogitando a divulgação irá divulgar informação favorável para a entidade e não irá divulgar informação desfavorável à entidade” (Dye, 2001, p. 184).

As informações de fatores de risco que não são descritas podem ser avaliadas sob o ponto de vista da seleção adversa, no qual ausência de informação palpável no relatório contábil para a tomada de decisão, estima-se que esta seja desfavorável ao usuário. Ademais, na ausência de distintas configurações quanto as narrativas de evidenciação, as mesmas perdem seu valor preditivo e de tempestividade, pois tendem ao longo do tempo serem atemporais. Desse modo, os ativos das empresas do setor elétrico podem ser visualizados de forma adversa, visto a ausência de informações que melhor possam caracterizar o valor da empresa, quando a variável observada é o risco (Salotti \& Yamamoto, 2005).

Os resultados desta investigação encorajam fortemente as empresas do setor elétrico a adotarem melhores práticas em seus relatórios de fatores de risco, visto que um choque como a crise hídrica tem a capacidade de afetar as operações de uma empresa. Por outro lado, a forma como o setor elétrico respondeu a tal contingência não é comunicada e o valor consultivo dos seus relatórios se perde, caso o mesmo não cumpre o seu papel na condução das decisões de investimentos no mercado de capitais.

\section{CONSIDERAÇÕES FINAIS}

O estudo objetivou analisar a configuração do conteúdo informacional divulgado nos formulários de referência relacionado aos fatores de risco das empresas do setor elétrico diante de uma crise hídrica. Os fatores de riscos foram segregados conforme as recomendações da Resolução n 480/2009 da CVM. Posto isso, as descrições evidenciadas nesta investigação estão consubstanciadas no interesse desta investigação, o qual consiste reconhecer as respostas das narrativas praticadas pelas organizações em períodos de crise, neste com foco período de crise hídrica, o qual inclui um período temporal de 2013 a 2015.

Os resultados apontaram que há uma diversidade de riscos divulgados pelas companhias, tendo os seguintes destaques: (i) decisões desfavoráveis de processos judiciais; (ii) impossibilidade de implementar totalmente a estratégia dos negócios; (iii) influência significativa do acionista controlador e possíveis conflitos de interesse; (iv) não garantia de pagamento de dividendos e juros sobre capital próprio; (v) falta de capacidade de pagamento de clientes; (vi) incerteza na obtenção de novas concessões ou renovação das atuais; (vii) problemas com as empresas terceirizadas; e (viii) poder discricionário da ANEEL na determinação das tarifas. Além disso, as companhias abordaram sobre o cenário hidrológico atípico do Brasil, o cenário político, a forte influência do Governo no setor e a falta de eletricidade e o consequente racionamento de energia. Entretanto, esta divulgação é realizada predominantemente de forma descritiva, sem ser consubstanciada em números e valores conforme preconiza a legislação.

Os resultados também revelam que as empresas praticamente não alteram suas políticas de evidenciação de um 
período para o outro e que existe uma padronização das informações divulgadas nos três períodos analisados, independente do cenário político, econômico e social, o que indica que são atemporais. Sinalizando algumas reflexões sobre sua finalidade e utilidade, questiona-se se esta forma de evidenciação é efetiva e útil e garante a eficiência do mercado. Alguns questionamentos sobre a finalidade da evidenciação dos fatores de riscos, sinalizam se realmente servem de suporte para a tomada de decisão dos stakeholders. Ressalta-se que as informações estão sendo divulgadas, as companhias atendem aos preceitos da Resolução n 480/2009 da CVM. Porém, é questionável se esta forma de evidenciação é efetiva e útil e garante a eficiência no mercado de capitais. Percebeu-se um rol de riscos divulgados narrativamente, sem evidenciação do grau de exposição e mecanismos para mitiga-los. Dentre as razões para este comportamento encontram-se a dificuldade em mensurar os riscos e as possíveis consequências comerciais e legais delas decorrentes, quando não confirmarem as expectativas expressas em valores.

No entanto, os achados requerem parcimônia, uma vez que se referem apenas às empresas, fatores de risco evidenciados e período pesquisado. Outra restrição é o fato da pesquisa abranger apenas o formulário de referência publicado pelas empresas e pode haver mais relatórios que evidenciam procedimentos referentes aos fatores de riscos. Além disso, a ontologia dos autores está presente na análise dos resultados, o que pode gerar compreensões distintas entre pesquisadores, assim como, diferentes entendimentos na análise de conteúdo das informações.

O estudo avança por não adotar uma tipologia de riscos e analisar qualitativamente as informações divulgadas, além de adotar uma escala numérica em detrimento da binária para apurar o nível de evidenciação. Os resultados deste estudo poderão ser utilizados pelas companhias pesquisadas, com intuito de melhorar a evidenciação das informações e pelos stakeholders na tomada de decisões. Além disso, geram reflexões sobre a efetividade de atos normativos e sobre a liberdade concedida por estes, cujas evidências sugerem que o simples fato de evidenciar não implica necessariamente em cumprimento da obrigação.

Assim, recomenda-se discussão entre pesquisadores, empresas reguladas ou não, empresas de auditoria, órgãos reguladores sobre a qualidade das informações divulgadas, no caso desta pesquisa, sobre fatores de riscos. Estudos adicionais podem aperfeiçoar questões relacionadas à uniformização das informações divulgadas pelas companhias e o cenário de precificações de ações, visto que já há antecedentes que ilustram que diante de crises o valor da firma também passa a ser observado e julgado a partir das narrativas sobre riscos realizadas pela mesma. Essa inquietação de pesquisa pode contribuir para verificar se as condições hidrológicas desfavoráveis podem afetar o resultado da empresa e sua performance gerencial.

Também se recomenda a realização de um estudo para analisar em que medida estas informações divulgadas são utilizadas por diferentes stakeholders, o que pode ocasionar em uma nova proposta de evidenciação dos fatores de risco visando a qualidade informacional. Outra oportunidade de pesquisa que se estende para o futuro da temática também paira na questão de identificar outros meios utilizados pelas empresas para divulgar informações sobre gerenciamento de riscos, com vistas a identificar elementos menos genéricos como a probabilidade desses riscos acontecerem, principalmente diante de crises. Por fim, fica em aberto se a escassez de informações sobre fatores de risco pode ser considerada uma resposta da forma com que a empresa realiza o gerenciamento de risco, fato que merece investigação futura.

\section{REFERÊNCIAS} neel.

Agência Nacional de Energia Elétrica (ANEEL). (2016). ANEEL. Recuperado em 04 mar. 2016. de http://www.aneel.gov.br/a-a-

Barros, C. M. E., Lopes, I. F., \& de Almeida, L. B. (2019). Efeito contágio da operação carne fraca sobre o valor das ações dos principais players do mercado de proteínas do Brasil e do México. Enfoque: Reflexão Contábil, 38(1), 105-122.

Beuren, I. M., \& Silva, J. O. (2015). Evidenciação da remuneração variável dos executivos nas maiores empresas brasileiras listadas na BM\&FBovespa. Enfoque: Reflexão Contábil, 34(3), 95-124.

Brasil. (1976). Lei 6.704/76 de 15/12/1976. Dispõe sobre a sociedade por ações e cria a estrutura jurídica necessária ao fortalecimento do mercado de capitais de risco no país. Recuperado em 05 abril, 2020, de www.cvm.gov.br.

Comissão de Valores Mobiliários. Instrução CVM 480, de 07 de dezembro de 2009. Dispõe sobre o registro de emissores de valores mobiliários admitidos à negociação em mercados regulamentados de valores mobiliários. Recuperado em 04 abr. 2016. de http://www. cvm.gov.br/legislacao/instrucoes/inst $480 . \mathrm{html}$.

Comissão de Valores Mobiliários (2011). OFÍCIO-CIRCULAR/CVM/SEP/N007/2011. Recuperado em 25 abril, 2020, de http:// www.cvm.gov.br/export/sites/cvm/legislacao/oficios-circulares/sep/anexos/oc-sep-0711.pdf.

Companhia Energética de São Paulo (2015). Formulário de Referência. Recuperado em 23 março, 2016, de http://ri.cesp.com.br/ wp-content/uploads/2015/05/FR-2015-V8.pdf.

Companhia Energetica do Maranhao (2015). Formulário de Referência. Recuperado em 23 março, 2016, de https://www.rad.cvm. gov.br/ENETCONSULTA/frmGerenciaPaginaFRE.aspx?NumeroSequencialDocumento=55332\&CodigoTipoInstituicao=2

Companhia Paranaense de Energia (2015). Formulário de Referência. Recuperado em 23 março, 2016, de http://ri.copel.com/ ptb/5937/56830.pdf.

CPFL Energia SA. (2015). Formulário de Referencia. Recuperado em 23 março, 2016, de https://cpfl.riweb.com.br/ListaGroup. aspx?IdCanalPai=lguLOh/UdchI9S5A+57Dnw==\&IdCanal=Hvte39hVxSjlA07BsSDlew==\&ano=2015. 
Dal Magro, C. B., Filipin, R., \& Fernandes, F. C. (2015). Gestão de riscos: análise da evidenciação de riscos nas concessionárias de rodovias listadas na Bovespa com base na metodologia COSO. ConTexto, 15(30), 57-75.

Dantas, J. A., Rodrigues, F. F., Rodrigues, J. M., \& Capelletto, L. R. (2010). Determinantes do grau de evidenciação de risco de crédito pelos bancos brasileiros. Revista Contabilidade \& Finanças-USP, 21(52), 1-27.

Duke Energy Int. Geração Paranapanema SA. (2015). Formulário de Referência. Recuperado em 23 março, 2016, de http://www. paranapanemaenergia.com.br/investidores/Paginas/InformacoesFinanceiras.aspx.

Dye, R. A. (1985). Disclosure of nonproprietary information. Journal of accounting research, 23(1), 123-145.

Empresa Metrop. Aguas Energia S.A. (2015). Formulário de Referência. Recuperado em 23 março, 2016, de http://www.emae.com. br/arquivos/internet/Investidores/Informacoes\%20Financeiras/FR/FR2015_V7.pdf.

Energisa Mato Grosso do Sul (2015). Formulário de Referência. Recuperado em 23 março, 2016, de https://ri.energisa.com.br/ ptb/597/ESA_FR_Versyo14_20160503.pdf.

Fernandes, F. C., de Souza, J. A. L., \& Faria, A. C. (2010). Evidenciação de riscos e captação de recursos no mercado de capitais: um estudo do setor de energia elétrica. Contabilidade, Gestão e Governança, 13(1), 59-73.

Fiirst, C., Pamplona, E., Haag, S., \& Silva, M. Z. (2017). Evidenciação de fatores de risco e deficiência do controle interno de empresas brasileiras com ADRs. Revista Ciências Sociais em Perspectiva, 16(31), 190.

Freitas, H. M. R., Cunha, M. V. M., Jr., \& Moscarola, J. (1997). Aplicação de sistemas de software para auxílio na análise de conteúdo. Revista de Administração da USP, 32(3), 97-109.

Itapebi Geração de Energia S.A. (2015). Formulário de Referência. Recuperado em 23 março, 2016, de https://www.rad.cvm.gov. $\mathrm{br} /$ ENETCONSULTA/frmGerenciaPaginaFRE.aspx?NumeroSequencialDocumento=55818\&CodigoTipoInstituicao=2.

Jin, L., Chen, C., Wang, X., Yu, J., \& Long, H. (2020). Research on information disclosure strategies of electricity retailers under new electricity reform in China. Science of The Total Environment, 25(710), 1-7.

Klann, R. C., Kreuzberg, F., \& Beck, F. (2014). Fatores de Risco Evidenciados pelas Maiores Empresas Listadas na BM\&FBOVESPA. Revista de Gestão Ambiental e Sustentabilidade, 3(3), 78-98.

Laudelino, J. A. S. \& Fernandes, F. C. (2008). Evidenciação de riscos de empresas que captam recursos no mercado de capitais brasileiro: um estudo do setor de energia elétrica. Anais do Congresso Brasileiro de Custos, Curitiba, PR, Brasil, 15.

Light Serviços de Eletricidade S.A (2015). Formulário de Referência. Recuperado em 23 março, 2016, de http://ri.light.com.br/ ptb/5516/55619.pdf.

Lopes, I. F., \& Beuren, I. M. (2016). Evidenciação da Inovação no Relatório da Administração: uma análise na perspectiva da Lei do Bem (Lei No. 11.196/2005). Perspectivas em Gestão \& Conhecimento, 6(1), 109-127.

Lopes, I. F., Beuren, I. M., \& Dametto, I. D. R. B. (2016). Evidenciação dos recursos aplicados em pesquisa, desenvolvimento \& inovação e da redução de carga tributária por empresas listadas na BM\&FBovespa. ConTexto, 16(32).

Machado, E. A., Cruz, A. P. C, Takamatsu, R. T., \& Lima, G. A. S. F. (2013). Evidências de disclosure de valor recuperável de ativos em firmas listadas no mercado acionário brasileiro. Revista Universo Contábil, 9(1), 86-103.

Miihkinen, A. (2013). The usefulness of firm risk disclosures under different firm riskiness, investor-interest, and market conditions: New evidence from Finland. Advances in Accounting, 29(2), 312-331.

Meurer, A. M., Lopes, I. F., \& Musial, N. T. K. (2018). EVIDENCIAÇÃO DE INVESTIMENTOS EM CAPITAL HUMANO NOS RELATÓRIOS DA ADMINISTRAÇÃO DAS MELHORES EMPRESAS PARA TRABALHAR. Revista Eletrônica de Estratégia \& Negócios, 10(3), 149-177.

Pamplona, E., Fiirst, C., Haag, S., \& da Silva, M. Z. (2020). Nível e determinantes de evidenciação de riscos em empresas brasileiras do setor de energia elétrica listadas na BM\&FBovespa. ConTexto, 20(45), 19-33.

Perobelli, F. F. C. (2004). Um modelo para gerenciamento de riscos em instituições não financeiras: aplicação ao setor de distribuição de energia elétrica no Brasil. Tese de Doutorado. Universidade de São Paulo, São Paulo, SP, Brasil.

Raffournier, B. (1995). The determinants of voluntary financial disclosure by Swiss listed companies. European accounting review, 4(2), 261-280.

Rio Grande Energia S.A. (2015). Formulário de Referência. Recuperado em 23 março, 2016, de https://cpfl.riweb.com.br/ListaGroup.aspx?IdCanalPai=lguLOh/UdchI9S5A\%2057Dnw==\&IdCanal=WpQmsXSr1ccTE2es630Q+A==\&ano=2016.

Salotti, B. M., \& Yamamoto, M. M. (2005). Ensaio sobre a teoria da divulgação. Brazilian Business Review - BBR, 2(1), 53-70.

Santos, J. G. C. D., \& Coelho, A. C. (2018). Value-relevance do disclosure: fatores e gestão de riscos em firmas brasileiras. Revista Contabilidade \& Finanças, 29(78), 390-404.

Tractebel Energia SA. (2015). Formulário de Referência. Recuperado em 23 março, 2016, de http://www.tractebelenergia.com. $\mathrm{br} / \mathrm{wps} / \mathrm{wcm} /$ connect/80331d97-b686-487f-8418-a4f479040ee9/FR+2015+\%28versao+CVM\%29.pdf?MOD=AJPERES\&CACHEID=ROOTWORKSPACE80331d97-b686-487f-8418-a4f479040ee9

Verrecchia, R. E. (2001). Essays on disclosure. Journal of accounting and economics, 32(1-3), 97-180.

Zonnatto, V. C. S., \& Beuren, I. M. (2010). Categorias de Riscos Evidenciadas nos Relatórios da Administração de Empresas Brasileiras com ADRs. Revista Brasileira de Gestão de negócios, 12(35), 141-155. 